\title{
Bodies Making Spaces: Understanding the Airport as a Site of Dissonance
}

\author{
Milica Trakilović
}

Amsterdam Airport Schiphol in the Netherlands is a veritable hub of networks, contact zones, and transfers. Boasting the title of third-largest airport in Europe in terms of number of passengers, it now processes approximately 60 million passengers yearly. Schiphol wants to be known for four intersecting qualities, being "efficient, reliable, sustainable, and inspiring" (Amsterdam Airport Schiphol). As a frequent flyer in and out Schiphol myself, I can attest to its fulfilling these aims: I always marvel at the speed and ease with which I am able to move through the airport, whether on my way to a gate or back from a trip. While going through many airports is a chore, being at Schiphol is almost a treat; as I effortlessly move from one section to the next, I am entertained by colourful and inviting shop displays, art objects, and informational posters and notices. Although this warm reception is part of Schiphol's aim to "provide smooth processes and good facilities and [do] everything in its power to guarantee its passengers a pleasant journey" and "to remain the preferred airport in Europe", (ibid.) my experience is not a universal

M. Trakilović $(\bowtie)$

Graduate Gender Programme - Department of Media and Culture Studies, Utrecht University, Utrecht, The Netherlands

(C) The Author(s) 2019

T. Lähdesmäki et al. (eds.),

Dissonant Heritages and Memories in Contemporary Europe,

Palgrave Studies in Cultural Heritage and Conflict, https://doi.org/10.1007/978-3-030-11464-0_5 
one. Indeed, Schiphol, like all airports, is very much a site of (invisible) border zones that will allow easy entry to some subjects, while prohibiting free movement to others.

In January of 2017, I spoke to a young Syrian who had come to the Netherlands in 2015, seeking asylum. More specifically, his place of arrival was Schiphol, but his experience of the place differed drastically from mine. While I routinely experience almost uninterrupted movement in this large and seemingly open space, my interviewee's ${ }^{1}$ stay at Schiphol was characterized by waiting and confinement. After introducing himself as a refugee to the Schiphol police, he spent seven days in the Schiphol detention centre while waiting for his request for asylum to be processed. During this time, his movement was severely restricted; he describes the detention centre as a "good prison", but a prison nevertheless. I take this personal account as the empirical starting point of my analysis, which will center on a phenomenological reading of the space of Schiphol Airport. I thereby join several other contributors to this book who have chosen to analyze particular spaces as sites of heritage dissonance, notably Iris van Huis and Sigrid Kaasik-Krogerus. In my analysis, Schiphol also emerges as a site of heritage dissonance.

Theorizing on the possibility of queering social spaces through the arrival of different bodies, Sara Ahmed writes that "the skin of the social might be affected by the comings and goings of different bodies, creating new lines and textures in the ways in which things are arranged" $(2006,9)$. At the same time, as Anssi Paasi notes, spaces are constantly being reworked and reconstructed based on unequal and hierarchical power relations, "in the sense that some actors are more actively participating in the production of space/scale while most people are 'consuming' and reproducing them" $(2001,13)$. In this chapter, I consider how the controlled movement of bodies in airports contributes to, and contests, both the European memory-heritage-identity complex (Macdonald 2013, 5) and the (Dutch) cultural archive (Wekker 2016). The former concept is useful in this analysis because it allows for an exploration of the airport as a historically, culturally, and politically entangled phenomenon, while the latter specifically addresses the ways in which the Dutch cultural canon, to which Schiphol belongs in my analysis, is built on an

\footnotetext{
${ }^{1}$ The interview was conducted in the context of the ERC project Bodies Across Borders in Europe: Oral and Visual Memory in Europe and Beyond on 14 January 2017 in Amsterdam, The Netherlands.
} 
imperial and colonial legacy. I will provide a phenomenological account of Schiphol Airport based on my interviewee's experience of arriving in the Netherlands as a Syrian national and applying for asylum. In the process, I am guided by the following question: To what extent are European cultural and national politics of belonging being promoted and enforced at airports in general, and Schiphol Airport in particular, through processes of detainment and control, and to what extent does Schiphol emerge as a site of heritage dissonance through this dynamic?

\section{Methodological Framework and Conceptual Approach}

\section{Space and Belonging}

In this chapter, I ask how spatiality and belonging are negotiated at the airport and how they impact on identity formation. At the same time, in no way do I want to produce a unitary, simplified, or homogenous conceptualization of identity, or any conceptual category for that matter. In her chapter in this volume, Tuuli Lähdesmäki has noted that identity has become a rather weak analytical category, and instead proposes the concept of belonging, as that indicates a process rather than a fixed position. I join her in this approach, particularly drawing on Marco Antonisch's $(2010,645)$ argument that any analysis of belonging should contain considerations both of personal feelings of being "at home" (or not) somewhere and of the broader discursive dimension that "constructs" belonging according to a particular social and spatial ordering, and in so doing produces a "politics of belonging". My analysis of Schiphol consists precisely of these two dimensions. My interviewee's embodied experience of arriving at Schiphol and being detained represents the first set of empirical data and the starting point of my analysis. From there, I extend the analysis to a broader observation of Schiphol's spatial ordering, which includes Schiphol's camp-like detention centre and the "open" space of the airport. With the latter, I pay particular attention to how certain objects, visuals, and discourses are disseminated, and what kind of politics of belonging is attached to them. I am informed by Benedict Anderson's formulation of the nation as an imagined community that rests in the imagined union of its national subjects $(2006,7)$, as well as Anthony Easthope's insistence that nations exist in their discursive dimensions (1999, iix). All of this suggests that cultural and national identities are performative rather than absolute, which also means that I 
am less interested in pinpointing what a national space may be and more in how it is brought into being, i.e. what cultural, organizational, and ideological practices are at the heart of these conceptualizations. That being said, in this analysis I do understand Schiphol Airport as a specifically European space according to a critical postcolonial/decolonial scholarly framework.

To think about spaces is to think about the kinds of bodies that can inhabit them. In other words, the question of spatiality is largely a question of bodily presence. In this chapter, I take a phenomenological approach in looking at the connection between spaces and bodies, which means that I am interested in actual bodily practices that make up somebody's being-in-the-world and the inevitable affective experiences that accompany these. I agree with Sharon Macdonald when she says that:

Giving attention to materialities not only recognizes the inevitably material nature of human existence but also opens up investigation of how the differential properties of particular materials, objects or technologies interact with human endeavour and understanding; in other words, what difference do the differences between things make? $(2013,84)$

Indeed, what difference do the differences between bodies and the way that they are positioned in space make? First of all, it is important to note how spatiality and understandings of belonging are and have always been inextricably linked. As Anssi Paasi observes: "Identity is not merely an individual or social category, but also - crucially — a spatial category, since the ideas of territory, self and 'us' all require symbolic, socio-cultural and/or physical dividing lines with the Other" (2001, 10). Paasi here not only points to the importance of recognizing the spatial and territorial logic of identity formation, but also its inherent hierarchical ordering. Since "space" (as a concept and a physical structure) can only exist if it is in some way delineated or defined, then it follows that identities require boundaries as well, if they are to be comprehensible, "readable". In this chapter, drawing on the conceptual work by Sara Ahmed in Queer Phenomenology (2006) and A Phenomenology of Whiteness (2007), I am taking a phenomenological approach by looking at how a spatial makeup and the controlled movement of bodies in spaces (airports in particular) bring into being and enforce dominant notions of national and cultural heritage, keeping in mind how these may be contested as well. 


\section{Europe and Race}

Many scholars have made the link between a European claim to colour blindness (notably El-Tayeb 2011; Goldberg 2006; Wekker 2016) and the dominant conception of spaces as (culturally, politically, and ideologically) "white". As Fatima El-Tayeb states in European Others:

To reference race as native to contemporary European thought, however, violates the powerful narrative of Europe as a colorblind continent, largely untouched by the devastating ideology it exported all over the world. This narrative, framing the continent as a space free of 'race' (and, by implication, racism), is not only central to the way Europeans perceive themselves, but also has gained near-global acceptance. $(2011, x v)$

El-Tayeb here speaks of the way in which European spaces have been imagined, and of the dominant cultural and symbolic framings and perceptions which have followed from the idea that Europe is a continent that is not influenced or "touched" by race. Theo Goldberg points out how, in order to maintain this ideal of a racially homogenous space, Europe has historically purged its territories from those considered nonwhite and/or non-European, both in a symbolic and in a literal sense, "repeatedly making the Different different so as to sustain the Same" (2011, 357). El-Tayeb joins him in this line of thought by illustrating how "Europeans possessing the (visual) markers of Otherness" will always stand outside of a conceptualization of European authenticity and thus will always carry the notion of "arrival" with them, even if they belong to the descendants of migrants who arrived to Europe decades before $(2011, \mathrm{xxv})$. This reinforces the racialized idea that there is a "proper Europeanness" (El-Tayeb 2011, xii), but the exclusionary logic on which this notion is built is difficult to critique or even point out.

Gloria Wekker comes to a similar conclusion with regards to the question of a racialized cultural identity in the Netherlands. She argues that identifying the "whiteness" of the dominant conception of Dutchness is "iconoclastic" (Wekker 2016, 2), because the racialized logic that is the foundation of this self-conception is completely disavowed. This dominant idea is part of the Dutch cultural archive, "an unacknowledged reservoir of knowledge and affects based on four hundred years of Dutch imperial rule" (ibid.) that informs the processes of making meaning on all levels (individual, institutional, and structural/symbolic). 
The cultural archive for Wekker is not located in any particular place, but it does inform behaviours, rules, knowledge, and emotions because it works as "a repository of memory, in the heads and hearts of people" (2016, 19), and thus also inevitably influences the spatial ordering of bodies and objects.

Wekker's notion of the cultural archive as a highly elaborate system in some respects echoes Sharon Macdonald's theory of the European memory complex, which she in fact points out is better referred to as "the memory-heritage-identity complex" (2013, 5). Both concepts point to the interrelation between the workings of memory, the construction of belonging, and the preservation and building of heritage sites/spaces where memory and identity come together. In fact, both Wekker and Macdonald emphasize the foundational importance in the European imaginary of World War II and the centrality of the Holocaust "as the epitome and model of racist transgressions" (Wekker 2016, 4), resulting in the cosmopolization of the memory of the Holocaust in Europe and beyond as well (Macdonald 2013, 214). The centrality of the Holocaust in European memory is also responsible for a "displacement" of European colonialism "off" the European shores and from European historical consciousness, which invokes the notion of Europe as a separate space free of racism all the more (Wekker 2016, 4). Theo Goldberg notes how the Holocaust serves as a reference point in the European imaginary which results in a "racial erasure" and an "evaporation" of colonial history from European shores $(2006,336)$. Both the (Dutch) cultural archive and the (European) memory complex are heavily informed by this historical moment.

All of these accounts are not meant to contribute to a homogenization of "European space", nor to imply that the Dutch cultural archive and the European memory complex are interchangeable and easily comprehensible phenomena. Highlighting the similarities between these concepts, however, should contribute to a deeper understanding of the place (and displacement) of racial minorities in the European imaginary, as well as that of actual European spaces. Theo Goldberg's concepts of racial europeanization and racial regionalization are of central importance here. While racial europeanization signifies the particular ways in which race is being done in Europe (the centrality of the Holocaust and the subsequent erasure of race being a prime example), racial regionalizations "exemplify the regionally prompted, parametered, and promoted racisms in the form of "racial europeanization"' (Goldberg 2006, 333). 
What this means is that distinct local characteristics still contribute to the overall idea of racial europeanization, keeping the idea of Europe as a racially "pure" territory in place, and hence it makes sense to see how the particular situation of the Netherlands fits into a larger European framework. Sharon Macdonald, in her ruminations on Europe as a memoryland, or rather memorylands, arrives at similar conclusions: "The indeterminacy of the singular or plural here is indicative of what is at issue" $(2013,2)$. Macdonald recognizes that there is an overarching, although by no means unvarying way of understanding and doing the past in Europe, while there are also significant variations on more local levels (ibid.). This tension between the national and the European can also be found at airports, as they are complex sites where European and national (Dutch) heritage are simultaneously enforced and contested. When talking about heritage, I am drawing on Višnja Kisić's conceptualization of "heritage dissonance", noting that the meaning of heritage is always contingent and never stable, since dissonance is always presented as "a passive potential" $(2017,29)$. Considering Schiphol as a site of dissonant heritage is useful since, as, according to Kisić, heritage is both a unifier and a simultaneous producer of difference, respectively represented in my argument by the airport and its detention centre. It is important to note, however, that dissonance does not always stand for contradiction, but can also point to the instability and negotiation of political processes and power relations $(2017,57)$.

\section{Bordering Processes}

European understandings of national belonging have been significantly influenced by the irregular migration that has marked the beginning of the twenty-first century, acquiring a particularly central position in popular and political debates since the European migration/refugee crisis at the beginning of 2015. As Henk Van Houtum (2010, 960) observes, anxieties around uncontrolled migratory masses in Europe have resulted in bordering, ordering, and othering, all three going hand in hand. They especially operate in today's EU (which is popularly and routinely collapsed into Europe), where the openness of its internal borders-according to the Schengen principle, at least, although this openness has been modified in light of the migration crisis and become more controlled-is counteracted by fortifying its external borders. The rise of, and support for, right-wing populism across Europe reflects 
the wish to keep unwanted others at bay and fortify outer boundaries which are perceived as having been weakened and being in dire need of restoring, which the Brexit phenomenon is an exemplary case of. Anssi Paasi $(2001,22)$ has noted that, out of all the continents, Europe is the youngest in the sense that European national boundaries have been collapsed, redrawn, and reworked the most in the past century. In Europe, national and ethnic belonging typically carry much more weight in how subjects identify themselves than a broader and perhaps more elusive European identity, resulting in differing accounts and opinions about what exactly constitutes that identity (Paasi 2001, 21). Yet it can be argued that it is precisely because there is no official account of what constitutes Europe that the idea of a singular European identity has emerged so strongly in recent years, clearly outlined against the constant "threat" of migration.

Indeed, in Memorylands, Sharon McDonald (2013, 37) discusses European histories and observes that identity-building is often predicated on invoking an "oppositional 'Other'", especially the Muslim Other, ${ }^{2}$ through different mechanisms of exclusion that can take various shapes: social, cultural, political, structural. In White Innocence, Gloria Wekker highlights "the fundamental impossibility of being both European, constructed to mean being white and Christian, and being black-migrant-Muslim-refugee" $(2016,21)$. Protecting the European space thus becomes synonymous with protecting an imagined European identity by erecting "a myriad of new invisible borders that are ideological, radicalized, and politicized" (Ponzanesi and Blaagaard 2011,3). This means that the process of monitoring, controlling, and surveilling those who are deemed as outsiders extends far beyond the official national and geographic borders zones into "diverging social practices and discourses" (Paasi 2001, 16). In other words, invisible bordering practices, propagated and upheld by social and structural actors and institutions, are just as instrumental as visible, official mechanisms of border control in producing the kind of segregation that makes it possible to speak and think of Europeanness as a solid and unquestioned project. Official bordering practices interact with invisible borders as ideological parameters and come together in the complex site of the airport.

${ }^{2}$ The figure of the Muslim especially carries with it a threat of death (Goldberg 2006, 345 ) and therefore inspires particularly high levels of apprehension and fear in the post$9 / 11$ moment. 
Processes of bordering are considered in this chapter in their ideological dimension, as something that is actively being done rather than something that simply is. Considering them in their processual dimension moves us to an understanding of borders not as spaces marked on a map, or onto territory, but instead as "actions that must be performed by human beings in relation to one another. Borders can be made to exist, and must be made in order to exist" (Whitley 2015, 14). Conceptualizing borders not according to what they are but according to how they are being done, which is a change in understanding borders not as ontology but as function (ibid. 16), allows me to trace the processes of inclusion/exclusion at Schiphol Airport which need to be actively maintained in order to sustain a particular notion of cultural/ national homogeneity. At the same time, understanding the processual logic of borders might even allow for a conceptualization of practices that challenge their exclusionary nature.

\section{Politics of the Airport}

Airports not (only) figure not as zones of transit, they also fulfil a political role. By looking at Amsterdam's Schiphol Airport specifically, I consider how this space represents a site of a specific and enforced notion of cultural heritage, a notion which is also always contested and under threat. While my observations could be extended to a broader analysis of airports as (European) cultural archives, I am following Sharon Macdonald's $(2013,6)$ "assemblage theory" approach of studying specific sites of knowledge and identity production so as to avoid generalizations and notice context specificities. This allows me to consider Schiphol Airport as a site where, first and foremost, the notion of the Dutch cultural archive is enforced, negotiated, and contested in a complex way, while Goldberg's conceptualization of racial Europeanization and racial regionalization allows me to still place these observations into a larger European framework and connect it to Macdonald's memory-heritageidentity complex.

I follow Debbie Lisle, who advocates for politicizing the airport as a site of "mediated power" $(2003,4)$. Understanding the airport as mediated means paying particular attention to how power relations there are always being negotiated, destabilized, challenged, and subverted. This Foucauldian strand of thinking allows us to see how an airport is never merely the site of extreme authority, control, and surveillance 
(although it is of course all of these things too). Rather, understanding power as mediated in airports makes it possible to consider how they are also sites of continually contested meanings, and this in turn allows me to see how the notion of cultural heritage and the practice of bordering take form and are challenged at this site. The point is that power, just like people, "never stays put at airports" (ibid.). At an airport, the border is, in Balibar's words $(2002,81)$, "polysemic" in the sense that it does not

have the same meaning for everyone, and indeed this differential meaning is essential to the function of the border [...] Border law enables some to pass national frontiers, while denying others; it upholds the freedom of circulation of some, while depriving others of this same freedom. (Whitley 2015, 17)

Airports as border sites have different meanings for different people and also actively work to produce those meanings: they can be sites of both national belonging and forced alienation. Although my own reading of Schiphol Airport pays more attention to the way in which power is used to control, monitor, and detain unwelcome bodies, as a tool of cultural hegemony, it is important to keep in mind how and where these mechanisms fail to exert their control. In what follows, I provide a phenomenological analysis of the airport, starting with my interviewee's experiential account.

\section{Phenomenology of the Airport}

\section{Peripheral Imaginaries}

In January 2017, I interviewed a young Syrian who recounted his journey coming to the Netherlands, and I draw here on his experiential account of arriving at Schiphol as an asylum seeker. As he had been working in Dubai for years before his departure, he describes his trajectory in light, easy terms, saying how he and the friend who was accompanying him were "laughing all the way". However, upon their arrival at Schiphol Airport, they spent an hour in front of the police office, paralyzed by the idea that they would have to introduce themselves as asylum seekers: "You know, your pride cannot allow you to say 'We're asking for asylum'". I would like to consider the disorienting experience that 
occurs once a request for asylum is uttered, and how this disorientation takes place on a discursive and phenomenological level. In other words, I am looking at where the category of asylum seeker or refugee places one in the social and cultural European fabric, but also at what it means spatially to move from traveller to asylum seeker; in this case, my interviewee was literally removed from the "open" 3 space of the airport into the closed space of the Schiphol detention centre, where he spent seven days while waiting for his case to be processed. He was removed from the airport the moment he "became" an asylum seeker; this social category precluded him from inhabiting the same cultural space as other travellers. Of course, this was done according to the official asylum procedure $^{4}$ in the Netherlands, but in this analysis I am more interested in the symbolic and cultural dimension of these bordering practices. He was not taken to the detention centre prior to his request. In other words, there was nothing in particular about his physical appearance that coded him as somebody seeking asylum. Rather, it was the utterance of the request that marked his body as one that should be removed from the premises of the open airport zone. The airport emerges in this case not as a site of empty signification, but very much as a national and even European space in which anxieties surrounding the collapse of cultural homogeneity routinely result in the removing and containment of undesirable bodies from public spaces, an ideology which I have already outlined above with the discussion of El-Tayeb, Wekker, Macdonald, and Goldberg. The asylum seeker in this case comes into being through a discursive (verbalizing the need for asylum) and spatial dimension (being removed from the airport to the airport detention centre).

\footnotetext{
${ }^{3} \mathrm{I}$ am aware that classifying airports as 'open' is somewhat of an oxymoron, especially considering how airports are becoming sites of ever more sophisticated mechanisms of surveillance, control, and restricted movement. However, in this case I contrast the relative openness of Schiphol Airport (mainly designed to facilitate travel) with the containment that characterizes the Schiphol detention center, where movement is controlled and restricted to a very high degree.

${ }^{4}$ One can apply for asylum at a Dutch border by reporting to the Immigration and Naturalization Service (IND). In case the person who is applying for asylum is arriving by either plane or boat from a non-Schengen zone, they are detained and must apply for asylum immediately, before crossing the external (Schengen) Dutch border, at the Application Centre of Schiphol Amsterdam airport (Aanmeldcentrum Schiphol, AC). The person arriving at Schiphol Airport will in most cases be detained by the Royal Military police. As those who are detained at Schiphol are not officially on Dutch territory, they can be expelled should their application be rejected (Ammeraal et al. 2014, 7, 22).
} 
Mark Salter $(2006,168)$ has noted that the global passport and visa regime is built on a confessionary logic that urges subjects to willingly present their bodies and data for scrutiny in order to be granted mobility. In this particular case, the confession is quite literal, since it is not stored in document but in a verbalization. Both the airport and the detention centre function as spaces with particular meanings: the airport is a space of transit because it is (presumably) made up by travellers, while, conversely, the detention centre is a space of (temporary) confinement because it is inhabited by asylum seekers/migrants/refugees. ${ }^{5}$ As Sara Ahmed points out in Phenomenology of Whiteness, "likeness is as an effect of the proximity of shared residence" $(2007,155)$. Spaces are coded in a certain way by the kind of bodies that (are allowed to) inhabit them. There is nothing intrinsically or fundamentally similar about these bodies, but it is their (forced) proximity that creates a certain kind of reading of that space. Accordingly, the Schiphol detention centre is a place of detention because it is inhabited by people coded as asylum seekers, while Schiphol Airport is a place of transit because it is inhabited by presumably cosmopolitan (inter)national subjects. The movements of these people are controlled and steered by biopolitical apparatuses (Foucault and Senellart 2008), managing the circulation of bodies through strategies of governance that are always political and power-laden. Yet, as power at the airport is mediated, this also means that it is possible to challenge these spatial orderings, however minutely. My interviewee was also aware of the fact that his request for asylum would effectively move him into the category of asylum seeker. However, in the hour he had spent working up to this moment, his presence was innocuous and undisturbed, and he was able to "pass" as one among many travellers. Although he was removed from the premises once he requested asylum, this turn of event also highlights to what extent seemingly homogenous national and cultural spaces are not "natural" but rather the result of selective processes that actively produce the notion of difference. As Salter notes, "passage through airports condition and normalize particular identities, certain authorities, and normalize ways of managing the mobility of a population" (2008, xii). As such, the existence of the detention centre in close proximity to the international airport becomes

${ }^{5}$ I do not mean to suggest that the terms migrant, refugee, and asylum seeker are interchangeable, but I cluster them together here to point to the classification of "undesirable others" in light of the 2015 European migration crisis. 
a condition upon which the smooth functioning of the airport is predicated, even if the existence of the detention centre is invisibilized.

The detention centre is, in other words, part of Schiphol's well-oiled machine; the openness of the airport is predicated on the detention centre functioning like a prison camp in which the movement of the contained subjects is monitored and controlled. The creation of camps is not only a way of ordering and containing an undesirable population, but, importantly, also a means of separating them from the "authentic" subjects (Van Houtum 2010, 971). Detention centres are routinely placed in remote and rural areas, ${ }^{6}$ reminiscent of the "out of sight, out of mind" principle: they are not really here if we do not see them or interact with them, or if we do not inhabit the same spaces. Interestingly, the Schiphol Application Center is located in the close vicinity of Schiphol Airport, and both are situated in the most densely populated area in the Netherlands, the metropolitan Randstad area. Here, detainment and "free" movement happen side by side, albeit in two distinctly separate spaces. Although the physical proximity between the two spaces is small, the space of the airport occupies a central position in the national imaginary (I will elaborate on this below), while the detainment centre is symbolically peripheral, and this distinction is upheld and enforced by the state. This is evinced, for instance, by the response to the fire at the Schiphol detention centre in October 2005 that claimed the life of eleven detainees. Although subsequent investigations ruled that the death toll was due to negligence of the guards on duty and the poor construction of the facilities, then-Minister for Integration and Immigration Rita Verdonk found that the staff had behaved "appropriately". Although the events sparked national outrage, the only party who was prosecuted was the inmate whose discarded cigarette was ruled to have started the fire. The state and government officials were not held responsible. Over the following years, a group of activists made efforts to commemorate the Schiphol fire and raise awareness of the events surrounding the deaths of the eleven detainees. In 2010, however, the final official commemoration of the victims took place, which was attended

\footnotetext{
${ }^{6} \mathrm{My}$ interviewee told me that after his seven-day detainment at Schiphol he was transported to an asylum center in the north-east of the country. He describes it as being "in the middle of nowhere" but nevertheless "the biggest one in the Netherlands," which is illustrative of the tendency to place large migrant populations in the least densely populated areas in the Netherlands.
} 
by some forty people. The annual commemorations were discontinued due to the public's lack of engagement and waning interest. For Judith Butler (2009), those whose deaths have occurred on the periphery of Europe constitute "ungrievable lives". My claim here is that the lives lost in the Schiphol fire are also peripheral in the sense that they do not occupy any significant component in the dominant national imaginary.

Mark Salter writes that: "Public and private authorities have taken advantage of the liminal character of airports to conduct policing and border functions, which take place inside the state but at the margins of the law. At the same time, more and more airports have accelerated lanes for the elite, transnational class and invisible corridors for the 'deportation class" (2008, xi). Schiphol Airport and its detention centre also operate according to this duality. My interviewee describes the process immediately following his request for asylum as follows:

It took like half an hour for the IND guys to come. They came. They took us. We walked like ten to fifteen minutes and then they took us to another building. No, first we did the fingerprints, and then they took us to another building which is in Schiphol but like a five-minutes drive. Which is the prison. I don't know if you've heard about this prison: There are drug dealers, there are criminals, there are asylum seekers who've been there a week if they're Syrians or Palestinians, or a few months if they're another [nationality]. Yes, it was like five days. At 9 p.m. they'd close all of us in a room. Then at seven in the morning they'd wake us up and then we got the one meal for the day, which is like breakfast and lunch. And then you can go out for an hour to play football or something. Yes, it's a prison. It's like a good prison, but it's a prison.

Here, the proximity of the detainment centre to Schiphol Airport is emphasized ("a five-minute drive") together with the distance between the bodies inhabiting the two spaces. Whereas the movement of people in the airport is relatively free (albeit organized), the movement of the people in detention is highly controlled and monitored. Moreover, the lumping together of different categories of unwanted others (drug dealers, criminals, asylum seekers) establishes a relationship of resemblance based on their physical location, as Ahmed has pointed out, and I find this also links to Balibar's conceptualization of "the duplication of the notion of the border" (Balibar 2002, 83). In that way, the asylum seekerillegal-criminal emerges as a complex construct that has no place inside 
the nation. As Charlie Hailey points out in Camps, these places of detention only serve to amplify concerns around unrestricted movements by foreign bodies. Such spaces can have an "open" or "closed" policy (the former refers to places that host people with very limited administrative and social rights, while the latter forcibly detain persons in one place). However, as Hailey states: "Less the resurgence of an authoritative political power, the camps are symptoms of a state's weakness and a resulting need to demonstrate the semblance of a policy of control" $(2009,244)$. What this means is that anxieties around uncontrolled migration prompt the building of special zones of confinement, which, when erected, prompt a fresh new wave of fear as they become the concrete embodiment of foreign bodies crossing European territories, perpetuating a vicious cycle. Meanwhile, the camps themselves become semi-permanent places of impermanence that some bodies can enter and leave freely (people like aid workers, camera crews, researchers, and reporters), while others cannot (the detainees themselves). Van Houtum $(2010,958)$ therefore speaks of

a constant border-work trying to separate the wanted from the unwanted, the barbarians from the civilised, and the global rich from the global poor in the territorial society. In so doing the EU increasingly is not only defining itself via its internal affairs, its ordering practices, but also by the production of new border rules and legislation towards its incoming migrants.

In other words, amplified anxieties around a "new" Other bring into being new ideas about a European culture that needs protection, which promotes the fortification of borders on all levels: social, cultural, political, institutional, territorial. While this bordering apparatus works according to particular structural orderings in each European nation state, they all promote the idea of a specific European space/identity union, as these bordering practices are specifically aimed at detaining and controlling people from outside of Europe. As Paasi notes: "The emergence of right-wing movements in European Union countriesand in many of those that are negotiating to get into the EU-shows that the links between (a bounded) space, culture, and politics are still full of political dynamite. It also shows how various spatial scales come together in the changing geographies of inclusion and exclusion" (2001, 23). Although Paasi's observations date back to 2001, they still astutely 
describe the political climate in many European countries after 2015. Detainment centres across Europe therefore contribute to "long-nurtured" European "civic drive to identify the foreign, to uphold the possibility of keeping the foreign, of permanently foreignizing the "(racially) non-European"' (Goldberg 2006, 354), an imperial gesture that is still being implemented in order to control the imagined migratory masses' movement into both imagined and actual European spaces.

\section{The Airport: Non-place or Heritage Site?}

Airports may be popularly considered as sites of "empty" signification because of the (visual, auditory, spatial) excess that characterizes them. This way, the airport is a "supermodern" site (Augé 2008), essentially devoid of meaning because it is too full of meaning; it represents too much, all at once (Lisle 2003, 6). However, this reading of the airport overlooks the ways in which these sites are imbued with cultural and national symbols that communicate specific meanings. Of course, national symbols at airports have a touristic and commercial value, and are typically found as items in souvenir shops, but they also "spill out of the souvenir shops" (Lisle 2003, 13). As I move through the different areas of Schiphol Airport, I am struck by the promotion of "typically" Dutch imagery that depicts commercialized aspects of Dutch culture: tulips, windmills, flat agricultural planes, and waterscapes. Typical and commercialized though they may be, Lisle describes these and other symbols as national heritage "at work" because of the "'official' narratives of nation they encourage" (ibid.). It must also not be forgotten that airports are the first and last impressions of a place (Iyer 1995, 54), and for national subjects, airports are the last and first impressions of "home" when they travel abroad. At Schiphol, there are now large screens installed at several locations, in- and outside the airport, showing videos with a goodbye or welcome-home message for a traveling loved one. These visuals amplify both the idea of "home" as well as that of the "homeland", and together with other symbols create the idea of Schiphol not only as a zone of transit but as a cultural space too. Sharon Macdonald $(2013,166)$ argues that ideas of national heritage in Europe have typically been disseminated through public institutions such as museums and monuments. A significant aspect of such objects and places is that they are "gathering grounds" for people to meet and experience 
"the nation" together. A current example of this is the Schiphol library. Opened in 2010, the first of its kind, the library houses books, movies, music, and small exhibitions by Dutch artists. These materials are offered to travellers on intercontinental flights so that they can learn more about Dutch history and culture, but they also serve to promote a particular politics of belonging, one connected to the Dutch past and its cultural canon. In this way, the airport also becomes a site of national heritage. This is also evinced by the fact that Schiphol occupies an important position in Madurodam, a popular park that showcases miniature replicas of Dutch heritage sites and landmarks of cultural significance. Schiphol has been featured in the park since 1952. This information can be found at the Schiphol website as well, which has a comprehensive overview of Schiphol's 100-year "rich history". A notable portion of this overview is dedicated to the occupation and destruction of Schiphol by German forces during WWII. The subsequent reclaiming and rebuilding of Schiphol is framed as Schiphol's phoenix-like rise from the ashes of destruction. Once again, the memory of WWII is centralized as defining moment. All of this points to the fact that Schiphol is not merely a transit zone (non-place), but a space with specific cultural roots tied to Dutch soil. Both its inception as well as its development to the international hub that it is now have always received great national attention and been well documented.

This way, the airport might be considered as one of the zones where cultural heritage and the cultural archive are made, negotiated, enforced, and contested. Wekker understands the cultural archive not as a single place or phenomenon where documents are stored, but rather as an accumulation of thoughts, feelings, and affects that shape the-in this case Dutch-cultural consciousness and canon. Importantly, Wekker notes that the cultural archive is built on a select body of memory that is frequently informed by the ways in which dominant understandings of Dutch colonial history are configured. Wekker states that the archive is to be found "in the heads and hearts of people in the metropole, but its content is also silently cemented in policies, in organizational rules, in popular and sexual cultures, and in commonsense everyday knowledge, and all of this is based on four hundred years of imperial rule" $(2016,19)$. My claim is that the airport does not stand outside of this logic; indeed, national and cultural markers are amplified here, making it a highly complex site where the cultural archive is played out. 


\section{CONCLUSION}

In this chapter, I have sought to answer the question of how notions of European national and cultural heritage and belonging are controlled, secured, and contested through the controlled movement, detainment, and separation of foreign bodies at airports. To do so, I have situated my analysis at Schiphol Airport in Amsterdam, basing it on the detainment experience as recounted by one of my interviewees. Taking a phenomenological approach propounding that the organization of spaces is made up by the bodies inhabiting them, I have sought to establish the link between space, materiality, and belonging, while not advocating for unitary conceptions of any of these concepts. Following this, I have drawn on the work of Fatima El-Tayeb, Gloria Wekker, and Theo Goldberg to point out how European spaces have been imagined as white/colour blind and are thus built on exclusionary practices. These practices largely take shape through the bordering processes that invoke the image of the "oppositional Other" who, in recent years, has been imagined as the (Muslim) migrant/refugee/asylum seeker. Following this, I have taken a closer look at how airports work as complex sites where power and belonging are constantly mediated.

Contrary to much of the literature on this topic, in this chapter airports do not feature as non-sites, but rather as places where notions of nationhood and cultural belonging are constantly enforced (and contested). The proximity between Schiphol Airport and the Schiphol detention centre forwards this enforced logic. Detaining difference in the name of cultural and national homogeneity then becomes a question of spatial ordering. The national subject or the undesirable Other are both very much shaped by the spaces they (are allowed to) inhabit, and this logic of inclusion/exclusion has the same imperial/racial roots that shape many European spaces; i.e. it is part of a European cultural heritage. However, this is not to claim or invoke Europe as a homogenous space where notions of heritage and the cultural archive are not and cannot be contested-rather the opposite. I agree with Sharon Macdonald when she emphasizes the need to recognize and acknowledge "cultural alternatives" since they "can not only unsettle assumptions but can also open up new possibilities by highlighting other routes - other ways of doing memory, heritage, and identity - that we might choose to take" (2013, 3 ). In this regard, it is important to keep in mind just how contested and multifaceted the notions of Europe and airports can be, both as concepts 
and as physical structures (airports, for instance, have been theorized to be either sites of no signification or with an abundance of signification). Finally, the chapter highlighted some of the dissonances and restrictions that shape the ordering of Schiphol as a site of heritage dissonance: the close proximity of the airport as an open space and the detention centre as a controlled space; the politics of belonging that is encouraged or discouraged in these places; and the peripheral or dominant memory practices that characterize both spaces.

Acknowledgements This work received funding from the European Research Council under the European Union's Seventh Framework Programme (FP/2007-2013), ERC Grant Agreement number 29585 (BABE).

\section{REFERENCES}

Ahmed, S. 2006. Queer Phenomenology: Orientations, Objects, Others. Durham and London: Duke University Press.

Ahmed, S. 2007. A Phenomenology of Whiteness. Feminist Theory 8 (2): 149-168.

Ammeraal, S., F. Borekhof, and A. van Kampen. 2014. Asylum Information Database National Country Report. The Netherlands. AIDA Project. http:// www.asylumineurope.org/sites/default/files/report-download/aida_-_netherlands_second_update_final_uploaded.pdf.

Amsterdam Airport Schiphol. 2017. http://www.schiphol.nl/en/schipholgroup/page/amsterdam-airport-schiphol/. Accessed 7 April 2017.

Anderson, B. 2006. Imagined Communities: Reflections on the Origin and Spread of Nationalism. London and New York: Verso.

Antonsich, M. 2010. Searching for Belonging-An Analytical Framework. Geography Compass 4 (6): 644-659.

Augé, M. 2008. Non-places: An Introduction to Supermodernity. London: Verso.

Balibar, É. 2002. What Is a Border? In Politics and the Other Scene, ed. É. Balibar, 75-86. London: Verso.

Butler, J. 2009. Frames of War: When Is Life Grievable? London: Verso.

Easthope, A. 1999. Englishness and National Culture. London and New York: Routledge.

El-Tayeb, F. 2011. European Others: Queering Ethnicity in Postnational Europe. Minneapolis: University of Minnesota Press.

Foucault, M., and M. Senellart. 2008. The Birth of Biopolitics: Lectures at the Collège de France, 1978-79. Basingstoke: Palgrave Macmillan.

Goldberg, D.T. 2006. Racial Europeanziation. Ethnic and Racial Studies 29 (2): 331-364.

Hailey, C. 2009. Camps: A Guide to 21st Century Space. Boston: MIT Press. 
Iyer, P. 1995. Where Worlds Collide. Harper's Magazine (August): 50-57.

Kisić, V. 2017. Governing Heritage Dissonance: Promises and Realities of Selected Cultural Policies. Amsterdam: European Cultural Foundation.

Lisle, D. 2003. Site Specific: Medi(t)ations at the Airport. In Rituals of Mediation, ed. C. Weber and F. Debrix, 3-29. Minneapolis: University of Minnesota Press.

Macdonald, S. 2013. Memorylands: Heritage and Identity in Europe Today. London: Routledge.

Place, Boundaries and Identity. European Journal of Urban and Regional Studies 8 (1): 7-28.

Ponzanesi, S., and B. Blagaard. 2011. In the Name of Europe. Social Identities 17 (1): 1-10.

Salter, M.B. 2006. The Global Visa Regime and the Political Technologies of the International Self: Borders, Bodies Biopolitics. Alterantives 31 (2): 167-189.

Salter, M.B. 2008. Politics at the Airport. Minneapolis and London: University of Minnesota Press.

Van Houtum, H. 2010. Human Blacklisting: The Global Apartheid of the EU's External Border Regime. Environment and Planning D: Society and Space 28 (6): 957-976.

Wekker, G. 2016. White Innocence: Paradoxes of Colonialism and Race. Durham and London: Duke University Press.

Whitley, L. 2015. More Than a Line: Borders as Embodied Sites. PhD dissertation, Goldsmiths College, University of London.

Open Access This chapter is licensed under the terms of the Creative Commons Attribution 4.0 International License (http://creativecommons.org/licenses/ by $/ 4.0 /)$, which permits use, sharing, adaptation, distribution and reproduction in any medium or format, as long as you give appropriate credit to the original author(s) and the source, provide a link to the Creative Commons license and indicate if changes were made.

The images or other third party material in this chapter are included in the chapter's Creative Commons license, unless indicated otherwise in a credit line to the material. If material is not included in the chapter's Creative Commons license and your intended use is not permitted by statutory regulation or exceeds the permitted use, you will need to obtain permission directly from the copyright holder.

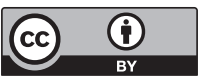

